\title{
APAKAH SAK ETAP MASIH PENTING BAGI AKUNTABILITAS UMKM?
}

\author{
Arif Widyatama1', Andi Sabirin'1, M. Ihsan², Jarudin'1 \\ 1Jurusan akuntansi, STIE Panca Bhakti Palu \\ 2Jurusan manajemen, STIE Panca Bhakti Palu \\ e-mail : arifwidyatama@stiepbpalu.ac.idd ${ }^{1}$, andisabirin01@gmail.com ${ }^{1}$, andiiccang84@gmail.com, \\ jarudin1997@gmail.com
}

\begin{abstract}
Abstrak
Tujuan penelitian ini untuk memahami mengenai penerapan SAK ETAP bagi akuntabilitas UMKM. Penelitian ini merupakan penelitian kualitatif dengan menggunakan paradigm intepretif yaitu dengan mengangkat fenomena atau masalah yang terjadi pada UKM Irwan Bengkel, dengan mengguanakan pendekatan interpretif peneliti ingin melihat pemahaman dari UKM dalam hal ini Irwan Bengkel dalam memahami penerapan SAK ETAP. Usaha Kecil dan Menengah (UKM) Irwan Bengkel belum melakukan pencatatan laporan keuangan sesuai dengan SAK ETAP. Hanya melainkan laporan yang tidak jelas pencatatanya; kedua faktor-faktor yang tidak terlaksananya pencatatan laporan keuangan berbasis (SAK ETAP) pada Usaha Kecil dan Menengah (UKM) Irwan Bengkel, ketiga keberadaan Standar Akuntabilitas Keuangan Entitas Tanpa Publik yang di peruntukan untuk Usaha Kecil dan Mengah tidak dikerahui oleh para pemilik usaha dan kurangnya sumberdaya manusia yang memiliki pemampuan menyusun laporan keuangan. dalam pengambilan keputusan pemilik masih menggunakan intuisi terakhir kurangnya sumberdaya manusia yang dimiliki terutama yang memiliki kemampuan dalam proses penyusunan laporan keuangan.
\end{abstract}

Kata Kunci: Penerapan SAK ETAP, Akuntabilitas UMKM, Interpretif, Penyusunan laporan keuangan

The purpose of this study is to understand the application of SAK ETAP for SMEs accountability. This research is a qualitative research using interpretive paradigm that is by raising the phenomenon or problem that occurs in SME of Irwan Bengkel, by using an interpretive approach the researcher wants to see the understanding of SMEs in this case Irwan Bengkel in understanding the application of SAK ETAP. Small and Medium Enterprises (UKM) Irwan Bengkel has not recorded financial reports in accordance with SAK ETAP. Only, but the report is not clear recording; second, factors that do not carry out the recording of financial statements based (SAK ETAP) in Small and Medium Enterprises (SMEs) Irwan Bengkel, thirdly, the existence of Non-Public Entity Financial Accountability Standards designated for Small and Medium Enterprises are not subject to business owners and the lack human resources who have the ability to prepare financial reports. in decision making the owner still uses the last intuition the lack of human resources possessed, especially those who have the ability in the process of preparing financial statements.

Keywords: Application of SAK ETAP, SMEs, Accountability, Interpretive, Preparation of financial statements 


\section{Pendahuluan}

Di Indonesia kelompok Usaha Kecil dan Menengah (UKM) merupakan sebuah kunci penggerak perekonomian suatu negara. Banyak UKM merupakan pengusaha kecil (home industry) (Spanò et al. 2019; Syailendra and Hamidah 2019; U and Majid AH 2015; Whiteley and Kölln 2018; Yang and Northcott 2019). Sehingga banyak konsumen dari UKM tersebut berasal juga dari kalangan menengah ke bawah. Oleh sebab itu, diharapkan nantinya geliat UKM ini dapat mendorong perekonomian lebih baik lagi, dikarenakan untuk penyerapan tenaga kerja masih didominasi oleh UKM.

Data menyebutkan tahun 2016 sektor UMKM mendominasi 99,9\% unit bisnis di Indonesia. Jenis usaha mikro yang paling mendominasi serta menyerap tenaga kerja tersebut. Sehingga diharapkan UKM dapat menjadi prioritas dalam meminimalisir pengangguran di Indonesia. Pemahaman dari UKM juga harus mencakup mengenai system yang terbentuk di dalamnya terutama system keuangan dari UKM tersebut. Hal ini penting dikarenakan system UKM ini menjadi dasar bagi pemilik dalam pengambilan keputusan. Pemilik UKM dapat mengambil keputusan mengenai usahanya dengan mengacu pada laporan keuangan, namun hal ini juga menjadi kelemahan dari UKM tersebut. Hal ini dikarenakan kompetensi dari UKM tersebut yang tidak mampu untuk mengikuti standar akuntansi keuangan dalam proses penyusunan laporan keuangan. Oleh sebab itu pemilik UKM harus mampu untuk menyusun laporan keuangan sebagai salah satu cara pengembangan usahanya (Ahmad and Barakat 2019; Boden et al. 2019; Han and Hong 2019; Kurniasih et al. 2019; Lukas, Neubert, and Schöndube 2019; Pandey and Sharan 2019; Spanò et al. 2019; Yang and Northcott 2019).

Namun pada saat ini masih banyak UKM belum mengetahui melakukan proses penyusunan laporan keuangan atau kinerja keuangan sesuai dengan SAK ETAP sehingga dalam melakukan pengembangan usaha dalam pengajuan kredit di Bank mengalami hambatan. Pihak Bank dalam proses pengajuan kredit harus membutuhkan jaminan dan dan bagaimana memaknai akuntabilitas laporan keungan sangat penting bagi kemajuan usahanya. Salah satu diantara UKM yang belum mengetahui pemaknaan akuntabilitas laporan keuangan adalah UKM Irwan Bengkel.

UKM Irwan Bengkel merupakan UKM yang bergerak dibagian servis motor dan menjual alat-alat motor, tepatnya di Munifrahman II (Palu Barat). Namun pada perjalanannya Irwan Bengkel memaknai laporan keuangan hanyalah sebuah angka atau laporan yang tidak berguna bagi usahanya. Dan pada akhirnya Irwan bengkel tidak melakuan pencatatan laporan keuangan yang tidak sesuai anjuran yang di tentukan SAK ETAP. Hal ini penting karena SAK ETAP dapat menjadi pedoman bagi pemilik UKM dalam menyusun laporan keuangan sehingga memiliki akuntabilitas yang diharapkan. Kontribusi penelitian ini adalah memberikan pemaknaan lain tentang konsep akuntabilitas menurut realitas dari UMKM.

Metode yang digunakan pada artikel ini menggunakan jenis penelitian kualitatif dengan menggunakan pendekatan interpretif. Tujuan dari paper ini adalah untuk memahami mengenai pemahaman dari pemilk UKM terkait dengan penerapan SAK ETAP. Peran dari SAK ETAP agar dapat menjadi pedoman bagi pada UKM agar dapat menyusun laporan keuangannya sehingg nantinya dapat menjadi cerminan representative dari kinerja perusahaan.

Hasil penelitian ini mengindikasikan bahwa UKM tersebut belum melakukan pencatatan laporan keuangan sesuai dengan SAK ETAP. Laporan keuangan yang dihasilkan tidak sesuai dengan pedoman yang ada di SAK. Bentuk pencatatan yang dilakukan hanya sebatas kegiatan penerimaan dan pengeluaran kas usahanya, tapi tidak mencerminkan seluruh akun yang ada diperusahaan, melainkan laporan yang tidak jelas pencatatanya.

\section{Metode}

Penelitian ini merupakan penelitian kualitatif dengan menggunakan paradigm intepretif yaitu dengan mengangkat fenomena atau masalah yang terjadi pada UKM Irwan Bengkel, dengan mengguanakan pendekatan interpretif peneliti ingin melihat pemahaman dari UKM dalam hal ini Irwan Bengkel dalam memahami penerapan SAK ETAP (standar akuntansi 
keuangan untuk Entitas Tanpa Akuntabilitas Publik) yang diterbitkan IAI (Jagoda et al. 2016; Johnstone 2020; Lukas, Neubert, and Schöndube 2019; Pahala et al. 2019). SAK ETAP sangat penting bagi satuan bisnis dalam menjadi pedoman dalam menyusun kinerja keuangan UKM. UKM Irwan Bengkel belum menetahui bagaimana membuat laporan keuangan dan bagaimana memaknai pentinya laporan keuangan untuk UKMnya. Makna akuntansi yang diungkap pada artikel ini adalah makna akuntabilitas yang dipahami oleh Pemilik Usaha Irwan Bengkel. Tahapan yang dilakukan adalah dengan melakukan proses wawancara kepada pemilik UKM tersebut. Kemudian dilakukan reduksi data. Selanjutnya mendeskripsikan temuan serta dari temuan tersebut dilakukan koding sehingga nantinya terbagi atas beberapa tema yang dianggap penting.

Berikut terdapat beberapa langkah yang peneliti lakukan dalam proses pengumpulan data. Peneliti akan mengumpulkan data dari hasil wawancara yang dialkukan, kemudian data tersebut akan dianalisis. Teknis dalam menganalisis data tersebut akan dibagi pada empat tahap yaitu pertama, peneliti akan menjabarkan fenomena yang terjadi secara detail dengan mengacu pada hasil wawancara yang telah dilakukan. Fenomena tersebut akan peneliti lakukan penjabaran sedetail mungkin dengan menjabarkan kualitas dari pengalaman informan. Kedua, peneliti akan mencari tema yang terdapat dalam hasil wawancara tersebut, sehingga peneliti dapat menemukan jawaban dari pertanyaan penelitian. Data yang telah diperoleh selanjutnya akan dibuat pada beberapa kategori sesuai dengan teman, konsep ataupun hal yang dianggap selaras (bracketing). Kemudian peneliti akan melakukan pengembangan noema dan noesis. Terakhir peneliti akan coba mengkorelasikan esensi dasar antara noema dan noesi.

\section{Hasil dan Pembahasan}

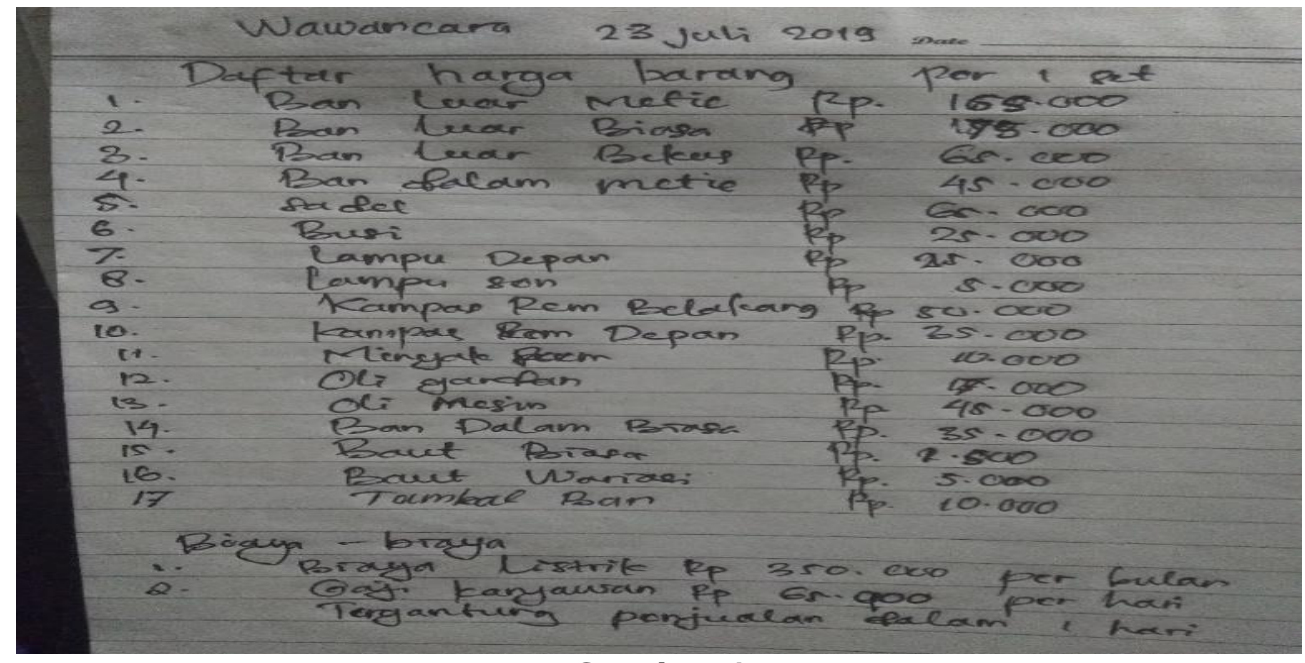

Gambar 1

Daftar pencatatan harga pembelian

Gambar 1 adalah hasil wawancara untuk memperkuat gambar diatas, tentang harga barang dan biaya-biaya yang dikeluarkan UKM perhari atau perbulan agar memudahkan peneliti menganalisis seberapa banyak keuntungan UKM dalam penjualan barang seara per unit. Namun pemilik tidak menyadari inilah bentuk pencatatan yang dimiliki oleh UKM nya, karena kurangnya pemahaman tentang bagaimana membuat laporan keuangan secara detail dan terstruktur sesuai SAK ETAP (Amirrudin et al. 2019; Chen, Gao, and Chen 2019; lyoha and Oyerinde 2010; Kim 2018; Pandey and Sharan 2019; Sharma and An 2018). Tujuan diterbitkannya SAK ETAP agar memudahkan bagi para pengusaha untuk mendapatkan tambahan dana dari perbankan, namun masih banyak UKM atau UMKM 
belum menerapkan bentuk pencatatan laporan keuangan sesuai SAK ETAP. Adapun hasil wawancara yang dilakuakan kepada Pak Irwan, beliau menyampaikan

"begini dek, kalau untuk sistem akuntabilitas dan pencatatan laporan keuangan sesuai SAK ETAP saya tidak mengetahunya sama sekali, karena bentuk pencatatan yang adik sebutkan baru saya dengar, dan saya hanya bisa mencatat dan menyebutkan nama dan harga barang dan biaya-biaya yang saya keluarkan secara perhari atau perbulan, dan kalau adik mau catat, catat saja soalnya tidak jelas bagaiman cara penulisannya."

Hasil wawancara serta pada gambar 1 menunjukkan bahwa pemilik UKM tidak mengetahui sama sekali mengenai system akuntabilitas. Hal yang dilakukan oleh pemilik UKM hanya mencatat dan menyebutkan nama dan harga barang dan biaya-biaya yang dikeluarkan secara perhari atau perbulan. Sehingga dari wawancara ini pencatatan yang dilakukan oleh pemilik UKM masih belum sesuai dengan pedoman SAK ETAP.

Berdasarkan hasil informasi di atas maka dapat ditarik sebuah simpulan bahwa pemilik UKM tidak menyadari bahwa bentuk pencatatan tentang nama dan harga barang serta biaya-biaya yang dikeluarkan merupakan bentuk akuntabilitas yang dibuat oleh usahanya, namun dalam proses pencatatannya masih belum sesuai dengan SAK ETAP (Ahmad and Barakat 2019; Amirrudin et al. 2019; Baldo 2012; Jagoda et al. 2016; Johnstone 2020; Khafid and Nurlaili 2017; Nyarku and Oduro 2018; Pahala et al. 2019; Sanders 1982; Widyatama and Yanida 2016; Yang and Northcott 2019). Hasil ini mengindikasikan bahwa pemilik UKM ini tidak membuat laporan keuangan sesuai dengan SAK ETAP.

Akuntabilitas pertanggungjawaban dapat diartikan sebagai kewajiban-kewajiban dari invidu-individu mengelola sumber-sumber yang bersangkutan dengan untuk pertanggungjawabkan kepada pihak eksternal.laporan keuangan dapat digunakan sebagai mekanisme untuk melakukan akuntabilitas. Pada UMKM informasi keuangan tersebut harus mengacu pada SAK ETAP (Alawattage, Graham, and Wickramasinghe 2019; Han and Hong 2019; Hasan Amir, Gusnardi 2019; Khafid and Nurlaili 2017; Kurniasih et al. 2019). Laporan keuangan yang dibuat oleh UKM seharusnya sesuai dengan SAK ETAP namun hasil wawancara ini menyebutkan bahwa pemilik UKM belum sama sekali membuat laporan keuangan yang sesui dengan SAK ETAP, melainkan hanya sebuah pencatatan yang menerakan nama bara dan pen centang jumlah barang yang terjual selama satu bulan.

Tidak hanya laporan keuangan yang andal menyulitkan pihak eksternal untuk memperoleh informasi mengenai kegiatan suatu usaha. Sehingga pihak eksternal akan sulit menganalisis suatu kinerja usaha tersebut. Sehingga keputusan tersebut tidak sesuai yang diharapkan. Penelitian ini akan menguak mengenai hal-hal yang menyebabkan kenapa UKM ini tidak melakuakan proses akunabilitas. Wawancara ini dilakuakan untuk memperoleh data yang mendalam dan berusaha memahami perasaan mereka dalam memahami tentang akuntabilitas. Adapun hasil wawancara narasumber yaitu pemilik UKM Irwan Bengkel, Pak Irwan beliau menyampaikan:

"begini dek, kalau untuk akuntabilitas ini saya sudah perna dengar tetapi saya belum perna memahami, apa itu akuntabilitas?, jadi saya hanya menganggap biasa saja tentang akuntabilitas itu sendiri, sedangkan kalo masalahnya denagan usaha ini saya hanya anggap biasa saja tentang akuntabilitas itu. Yang penting saya ketahui seberapa banyak penjualan setiap harinya."

\section{Kalo laporan pertanggung jawaban begitu Pak, Bapak Pernah buat?}

"jadi begini dek, dulu pernah saya buat pencatatan namun saya kurang memahami pencatatan tersebut, karena pencatatan itu di buat oleh adik saya yang sekarang bekerja di perusahaan Morowali."

Hasil wawancara tersebut menyebutkan bahwa pada dasarnya secara sederhana pemilik UKM sudah pernah melakukan bentuk pencatatan sebagai bentuk akuntabilitas namun pemilik UKM melakukan bentuk akuntabilitas itu hanya didampingi oleh pihak ketiga yaitu adiknya, sedangkan pemilik UKM tersebut tidak mengetahui bentuk pencatatan. . Berdasarkan hasil diatas peneliti dapat menarik kesimpulan, bahwa proses pencatatan yang 
ada didalam suatu usaha haruslah betul dan sesuai kriteria pencatatan dalam SAK ETAP. Hasil penelitian ini menunjukkan bahwa pencatatan yang dilakukan hanya sebatas mencata penerimaan dan pengeluaran UKM tersebut selama hari ini. Namun format yang dibuat masih sangat jauh dari pedoman SAK ETAP.

Bentuk pertanggungjawaban sebenarnya telah dilakukan oleh UKM ini namun belum sesuai panduannya. Seperti yang telah disebutkan sebelumnya bahwa SAK ETAP merupakan sebuah guide atau pedoman bagi UKM dalam menyusun laporan keuangan sebagai bentuk kinerja yang dilakukan. (Amirrudin et al. 2019; Dalla Via, Perego, and van Rinsum 2019; lyoha and Oyerinde 2010). Adapun bentuk pencatatan (akuntabilitas) yang dibuat Usaha Kecil dan Menengah (UKM) sebagai berikut:

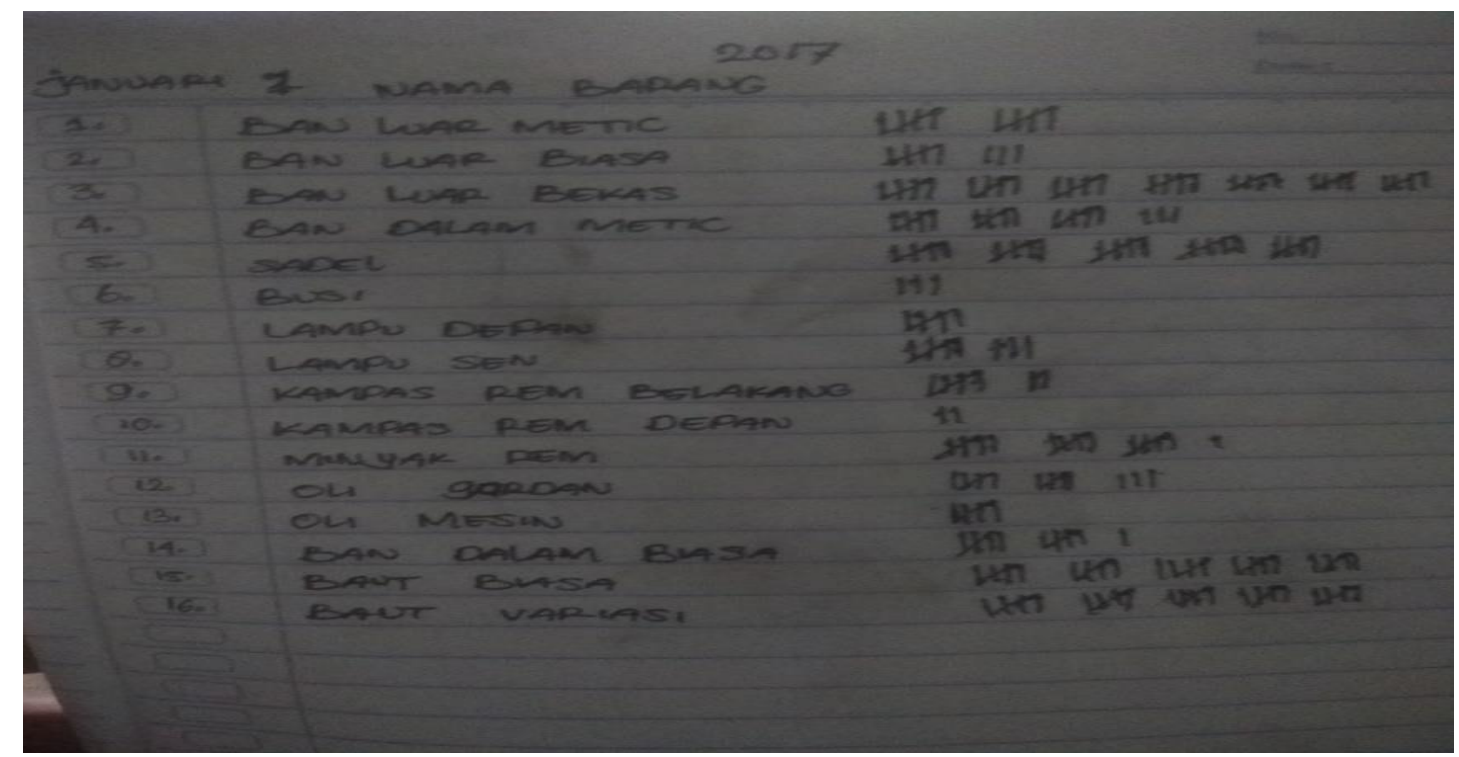

Gambar 2.

Pencatatan Persediaan dagang

Tujuan laporan keuangan adalah menyediakan informasi mengenai posisi kekayaan perusahaan, kinerja keuangan, serta modal perusahaan guna sebagai dasar dalam pengambilan keputusan. Namun pada perjalanannya pemilik UKM tidak memahami mekanisme pencatatan laporan keuangan diatas. Karena yang membuat laporan keuangan tersebut adalah adik dari pemilik UKM. Adapun hasil wawancara dengan Pak Irwan tentang apa tujuan kenapa membuat pencatatan itu.

"Begini dek, adapun tujuan kenapa saya melakukan pencatatan ini adalah untuk mengetahui sebererapa banyak pendapatan secara perbulan, namun pada perjalanannya saya kebingungan karena pencatatannya tidak jelas karena tidak ada harga yang tertera di dalam pencatatan itu. Karena yang membuatkan pencatatan itu adalah adik saya dan dia belum sempat memberitahukannya kepada saya bagaimana mekanisme yanga ada di dalamnya. Karena sebelum adik saya memberitahukan kepada saya bagaimana proses pencatatan yang dibuatnya, adik saya langsung ke Morowali ketiaka mengetahui ada perusahaan yang penerimaan karyawan. Dan pada saat itu pula saya tidak membuat suatu pencatatan untuk usaha ini"

Pada hasil wawancara tersebut dapat diuraikan bahwa pada dasarnya pencatatan telah dilakukan oleh perusahaan. Pencatatan ini juga merupakan bagian dari akuntabilitas, namun pencatatan ini tidak mengacu pada SAK ETAP. Pencatatan yang dilakukan hanya berupa penerimaan yang diperoleh selama sebulan yang merupakan hasil rekapan dari penerimaan dan pengeluaran selama sebulan sehingga diperoleh pendapatan selama sebulan. Namun dari hasil pendapatan tersebut pemilik tidak menyisihkan pendapatannya untuk penyusutan dari asset tetap. UKM Irwan Bengkel seharusnya menyisihkan uang 
tersebut namun pada kenyataannya UKM Irwan tidak melakukan hal tersebut sebagai beban penyusutan.

Selain itu dikarenakan ketidakmampuan dari pemilik UKM tersebut dalam mengelola keuangannya maka pemilik tersebut menghubungi pihak lain dalam hal ini adalah adiknya yang kebetulan saat itu mengetahui mengenai pencatatan. Namun ketika adiknya tidak bisa mendampingi pemilik maka UKM tersebut kembali seperti semula yaitu tidak paham mengenai pencatatan dalam membuat agar UKMnya lebih akuntabel.

Peneliti dapat menyimpulkan bahwa salah satu kurangnya pencatatan laporan keuangan bagi setiap UKM adalah karena kurangnya pemahaman tentang proses pencatatan laporan keuangan yang ada pada SAK ETAP, mengingat sistem pencatatan yang mereka buat hanyalah laporan keuangan sederhana yang belum sesuai dengan SAK ETAP. Hal ini sesuai dengan hasil penelitian Pahala et al. (2019) yang menyebutkan bahwa salah satu indicator yang menyebabkan rendahnya penyusunan laporan keuangan adalah kompetensi yang dimiliki oleh UKM masih sangat rendah.

Ketika melihat SAK ETAP, sebenarnya peran SAK ETAP dapat menjadi sebuah pedoman bagi UKM Irwan Bengkel sebagai bentuk akuntabilitas. Apabila kita melihat Tujuan laporan keuangan adalah menyediakan informasi mengenai posisi kekayaan perusahaan, kinerja keuangan, serta modal perusahaan guna sebagai dasar dalam pengambilan keputusan. Prinsip-prinsip SAK ETAP penting diperhatikan oleh pengusaha agar pengelolaan bisnis lebih baik sehingga usaha yang dimiliki menjadi lebih berkembang. Apabila SAK ETAP diterapkan oleh setiap usaha pihak per Bank kan akan respon dengan positif, karena akan mempermudahkan perbankan untuk menilai kelayakan bisnis tersebut untuk mengelola bantuan kredit pengembangan usaha. Disamping itu, suatu usaha akan memiliki data (keuangan) akurat yang berguna bagi setiap usaha agar dapat meningkatkan penjualan di usahanya. Hasil wawancara Bapak Irwan mengenai masalah yang dihadapi selama tidak melakukan pencatatan laporan keuangan yaitu:

"agak sulit kita dalam pengendalian karena tidak punya semacam catatan yang bagus dalam hal ini laporan keuangan walaupun laporan keuangan sederhana untuk mengetahui berapa tingkat penjualan selama 1 bulannya."

Berdasarkan hasil informasi diatas diperoleh kesimpulan bahwa usaha ini belum melakukan pencatatan laporan keuangan sederhana yang dibuat sendiri oleh pemilik UKM untuk proses pertanggung jawaban kedepannya. Sehingga dapat disimpulkan bahwa laporan keuangan yang mengacu pada pedoman SAK ETAP dapat menjadi dasar keputusan namun dengan rendahnya kemampuan tersebut maka terkadang keputusan yang diambil tidak sesuai dengan data yang tersedia. Standar keuangan dibuat dengan tujuan untuk memberikan kemudahakn dalam proses menyusun laporan keuangan. Namun dalam penerapannya masih terdapat kendala yang dipahami.

Namun, informasi yang dihasilkan harus lebih relevan dan andal terutama dalam pengambilan keputusan. Kendala yang sering dihadapi adalah kondisi yang tidak ideal dalam mewujudkan informasi tersebut. Berdasarkan hasil pengamatan wawancara yang sudah dilakuakan ditemukan kendala yang dihadapi Pak Irwan yaitu:

Karyawan atau pemilik UKM Irwan Bengkel tidak mencatatat atau membuat laporan keuangan. Yang mereka lakukan, karyawan dengan pekerjaanya dan pemilik UKM hanya bertugas menerima uanga ketika ada barang yang terjual tanpa melakuakan proses pencatatan. Berikut hasil wawancara dengan pak Irwan dan menyatakan bahwa

"adapun kendala yang saya hadapi dek, samapai saya tidak melakukan pencatatan laporan keuangan, kerena kuranya pemahaman mengenai proses pencatatan laporan keuangan."

Berdasarkan informasi tersebut bahwa karyawan ataupun pemilik UKM tidak melakuakan proses pencatatan sedikit pun, padahal proses pencatatan laporan keuangan sangatlah penting mengingat untuk mengetahui seberapa besar laba dan rugi setiap periode akuntansi. Hasil ini didukung dengan penelitian yang dilakukan oleh (Ahmad and Barakat 2019; Alawattage, Graham, and Wickramasinghe 2019; Amirrudin et al. 2019) yang mengatakan bahwa rendahnya penyelenggaraan dan penggunaan informasi akuntansi 
dalam pengelolaan UMKM disebabkan oleh persepsi terhadap pentingnya keberadaan informasi akuntansi bagi UMKM. Tidak adanya proses pencatatan dan membuat laporan keuangan, karena pemilik UKM dan sekaligus pengelola usaha. Berikut hasil wawancara dengan pak Irwan dan menyatakan bahwa.

"adapun kenapa saya tidak melakuakan pencatatan, untuk mencatat penjuan selama perhari, karena saya juga ikut membantu karyawan saya, ketika mendapat pelanggan yang banyak."

Berdasarkan informasi di atas peneliti dapat menarik kesimpulan, ketika ada salah satu yang mencatatat dan membuat laporan keuangan tentua akan bisa membantu pemilik UKM menghitung laba dan rugi setiap periode akuntansi. Artinya para pelaku usaha masih kebingungan tentang bagaimana usahanya bisa membuat laporan keunagan, salah satunya karena kurangnya tenaga kerja atau karyawan yang memahami proses pencatatan laporan keunagan. Sehingga diharapkan nantinya akuntabilitas dari UKM tersebut lebih baik (Widyatama and Yanida 2016).

Hambatan ini menimbulkan banyak masalah bagi UKM terutama ketika tidak mengambil keputusan berdasarkan data keuangan dalam perusahaan. Kecenderungan dalam pengambilan keputusan hanya berdasarkan dari intuisi atau pengalaman yang telah dilalui akibat yang diperoleh adalah pemilik UKM cenderung salah dalam pengambilan keputusan.

\section{Simpulan dan Saran}

Hal yang dapat disimpulkan dari pembahasan sebelumnya yaitu Usaha Kecil dan Menengah (UKM) Irwan Bengkel belum melakukan pencatatan laporan keuangan sesuai dengan SAK ETAP. Hanya melainkan laporan yang tidak jelas pencatatannya. UKM Irwan Bengkel ini belum melakukan pencatatan laporan keuangan sederhana yang dibuat sendiri oleh pemilik UKM untuk proses pertanggungjawaban kedepannya. Sehingga dapat disimpulkan bahwa laporan keuangan yang mengacu pada pedoman SAK ETAP dapat menjadi dasar keputusan namun dengan rendahnya kemampuan tersebut maka terkadang keputusan yang diambil tidak sesuai dengan data yang tersedia. Standar keuangan dibuat dengan tujuan untuk memberikan kemudahakn dalam proses menyusun laporan keuangan. Namun dalam penerapannya masih terdapat kendala yang dipahami. Selanjutnya adalah faktor inkompetensi yang dimiliki oleh pemilik Usaha Kecil dan Menengah (UKM) Irwan Bengkel dalam menyusun laporan keuangan sehingga ketidakmampuan ini menyebabkan pemilik UKM ini tidak menggunakan pedoman SAK ETAP dalam membuat laporan keuangan sehingga pemilik UKM lebih abai dalam menyusun laporan keuangan ini dalam proses pengambilan keputusan. Ketiga keberadaan SAK ETAP yang diperuntukan oleh UKM tidak diketahui dengan jelas oleh pemilik UKM Irwan Bengkel sehingga dalam pengambilan keputusan pemilik masih menggunakan intuisi terakhir kurangnya sumberdaya manusia yang dimiliki terutama yang memiliki kemampuan dalam proses penyusunan laporan keuangan.

Implikasi penelitian ini adalah bagi pemilik UKM dapat merekrut minimal satu karyawan yang memiliki kemampuan dalam proses penyusunan laporan keuangan dalam hal ini memiliki background akuntansi sehingga lebih paham dalam memahami penyusunan laporan keuangan. Kemudian bagi IAI dapat memberikan sosialisasi dan pelatihan kepada UKM mengenap penerapan SAK ETAP agar dapat memudahkan dalam penyusunan laporan keuangan. Kemudian, implikasi selanjutnya adalah IAI memberikan bantuan kepada UKM yang belum mampu menerapkan SAK ETAP dalam penyusunan laporan keuangannya.

Perlu adanya penelitian lebih lanjut mengenai penelitian mengenai akuntabilitas dalam konteks UKM dengan menambahkan aspek instuisi dengan membandingkan mengenai fungsi SAK ETAP atau instuisi yang dapat digunakan sebagai pengambilan keputusan. Selain itu, perlu ditambahkan unsur budaya kerja yang dimiliki oleh masing-masing UKM yang bisa menjadi pembeda hasil penelitian. 


\section{Daftar Pustaka}

Ahmad, Ayman Taha Hassan, and Khaled Barakat. 2019. "Impact of Accountability on the Performance of Police Service: Palestinian Police Case Study." Journal of Public Affairs 19(2): $1-10$.

Alawattage, Chandana, Cameron Graham, and Danture Wickramasinghe. 2019. "Microaccountability and Biopolitics: Microfinance in a Sri Lankan Village." Accounting, Organizations and Society 72: 38-60.

Amirrudin, Mira Susanti, Mazni Abdullah, Nooraslinda Abdul Aris, and Nor Farizal Mohammed. 2019. "Are SMEs Ready for Integrated Reporting? The Malaysian Experience of Accountability." International Journal of Financial Research 10(5): 30112.

Baldo, Mara Del. 2012. 16 Journal of Management and Governance Corporate Social Responsibility and Corporate Governance in Italian SMEs: The Experience of Some "Spirited Businesses."

Boden, Matthew Tyler, Clifford A. Smith, John W. Klocek, and Jodie A. Trafton. 2019. "Mental Health Treatment Quality, Access, and Satisfaction: Optimizing Staffing in an Era of Fiscal Accountability." Psychiatric Services 70(3): 168-75.

Chen, Cheng, Jinlong Gao, and Jianglong Chen. 2019. "Behavioral Logics of Local Actors Enrolled in the Restructuring of Rural China: A Case Study of Haoqiao Village in Northern Jiangsu." Journal of Rural Studies (December 2018): 1-11. https://doi.org/10.1016/j.jrurstud.2019.01.021.

Dalla Via, Nicola, Paolo Perego, and Marcel van Rinsum. 2019. "How Accountability Type Influences Information Search Processes and Decision Quality." Accounting, Organizations and Society 75: 79-91. https://doi.org/10.1016/j.aos.2018.10.001.

Han, Yousueng, and Sounman Hong. 2019. "The Impact of Accountability on Organizational Performance in the U.S. Federal Government: The Moderating Role of Autonomy." Review of Public Personnel Administration 39(1): 3-23.

Hasan Amir, Gusnardi, Muda Iskandar. 2019. "The Prospect of Accounting Standard Implementation: Micro, Small, and Medium Entities Based on Quality of Effective Applicable Financial Statement On January 01, 2018 (Study on Small Enterprises in Rokan Hulu District)." International Journal of Scientific \& Technology Research 8(9): 2108-12.

Iyoha, F. O., and D. Oyerinde. 2010. "Accounting Infrastructure and Accountability in the Management of Public Expenditure in Developing Countries: A Focus on Nigeria." Critical Perspectives on Accounting 21(5): 361-73. http://dx.doi.org/10.1016/j.cpa.2009.06.002.

Jagoda, Kalinga, Xiaohua Lin, Victoria Calvert, and Shaw Tao. 2016. "Accountability of Venture Support Agencies: Do They Really Help?" Entrepreneurship Research Journal 6(2): 175-206.

Johnstone, Leanne. 2020. "A Systematic Analysis of Environmental Management Systems in SMEs: Possible Research Directions from a Management Accounting and Control Stance." Journal of Cleaner Production 244.

Khafid, Muhammad, and Diah Nurlaili. 2017. "The Mediating Role of Accountability in the Influence of Cooperative Characteristics on Its Financial Performance." International Journal of Economic Research 14(5): 191-200.

Kim, Yoonho. 2018. "Analyzing Accountability Relationships in a Crisis: Lessons From the Fukushima Disaster." American Review of Public Administration 48(7): 743-60.

Kurniasih, D., P. I. Setyoko, M. Imron, and S. S. Wijaya. 2019. "The Role of Stakeholders in 
the Accountability of Village Enterprise Management: A Public Governance Approach." IOP Conference Series: Earth and Environmental Science 255(1).

Lukas, Christian, Max Frederik Neubert, and Jens Robert Schöndube. 2019. "Accountability in an Agency Model: Project Selection, Effort Incentives, and Contract Design*." Managerial and Decision Economics 40(2): 150-58.

Nyarku, Kwamena Minta, and Stephen Oduro. 2018. "Effect of Legal and Regulatory Framework on SMEs Growth in the Accra Metropolis of Ghana." International Journal of Entrepreneurship and Innovation 19(3): 207-17.

Pahala, Indra, Made Sudarma, Sutrisno, and Rosidi. 2019. "Accountability in Stakeholders Perspective: Views from State University of Jakarta with a Phenomenological Approach." Academy of Accounting and Financial Studies Journal 23(2): 1-8.

Pandey, Gavendra, and Maithili Sharan. 2019. "Accountability of Wind Variability in AERMOD for Computing Concentrations in Low Wind Conditions." Atmospheric Environment 202(May 2018): 105-16. https://doi.org/10.1016/j.atmosenv.2019.01.017.

Sanders, Patricia. 1982. "Phenomenology: A New Way of Viewing Organizational Research." The Academy of Management Reveiw 7(3): 353-60.

Sharma, Umesh, and Yi An. 2018. "Accounting and Accountability in Fiji: A Review and Synthesis." Australian Accounting Review 28(3): 421-27.

Spanò, Rosanna, Alessandra Allini, Marco Maffei, and Annamaria Zampella. 2019. "Knowledge, Innovation, and Control towards Accountability: A Comparative Case Study." Technology Analysis and Strategic Management 31(6): 720-31. https://doi.org/10.1080/09537325.2018.1545999.

Syailendra, Gede Dion, and Hamidah Hamidah. 2019. "Makna Profesionalisme Bagi Diri Petugas Pemeriksa Pajak." Jurnal Akuntansi Multiparadigma 10(2): 241-61.

U, Ahmed, and Abdul Majid AH. 2015. "Role and Impact of Reward and Accountability on Training Transfer." Business and Economics Journal 07(01): 1-6.

Whiteley, Paul, and Ann Kristin Kölln. 2018. "How Do Different Sources of Partisanship Influence Government Accountability in Europe?" International Political Science Review.

Widyatama, Arif, and Maria Yanida. 2016. "Akuntabilitas Keuangan UMKM: Bagaimana Perspektif Dari Sebuah UMKM Bidang Perdagangan?" Journal of Research and Applications: Accounting and Management 1(3): 202.

Yang, Cherrie, and Deryl Northcott. 2019. "How Can the Public Trust Charities? The Role of Performance Accountability Reporting." Accounting and Finance. 